Encuentro No. 103, 44-46, 2016

\title{
Avances y desafíos del sector minero nicaragüense
}

\author{
Daniel Corrales Pérez*
}

\section{Recibido: enero de 2016 / Aceptado: marzo de 2016}

El concepto de minería sostenible en los últimos años ha venido adquiriendo auge y, por consiguiente, ha convertido a la industria en una actividad económica atractiva en muchos lugares del mundo debido a la serie de beneficios socioeconómicos que genera la minería en general. Sin embargo, existen impactos de diversas índoles y particularmente ambientales que deben ser mitigados para contribuir a la conservación y protección de los ecosistemas naturales y bienestar de la salud humana.

Existen empresas mineras en el mundo (América del Norte, América del Sur, Europa, Oceanía) que han experimentado casos exitosos en cuanto a la sostenibilidad del agua, uso de energías renovables, manejo de residuos líquidos-sólidos-gaseosos, así como, mejoraras en áreas de relaciones comunitarias, institucionalidad, legislación, entre otros.

La gestión y manejo ambiental dentro de las instalaciones mineras se ha realizado a través de la construcción de obras de ingeniería para la disposición de desechos, mejoras en la eficiencia de las técnicas utilizadas para el procesamiento mineral, y el reciclaje, reutilización y reuso de los desechos de minas. Por otro lado, muchas empresas mineras durante y después de finalizada la vida útil de las minas, han comenzado a planificar para el cierre y restauración de los sitios mineros con la finalidad de garantizar la seguridad de las personas que habitan en los alrededores de las minas, así como la protección del medio ambiente.

El conjunto de prácticas, medidas y estrategias de gestión y manejo ambiental, han sido desarrolladas y complementadas con tecnologías emergentes y el cumplimiento de un estricto marco jurídico, que regula y controla las actividades mineras en cada país.

Carrera de Ingeniería en Calidad Ambiental, Departamento de Desarrollo Tecnológico, Facultad de Ciencia, Tecnología y Ambiente, Universidad Centroamericana, Managua. Correo electrónico: geoquimica72@gmail.com. 
En el pasado poca atención fue dada al manejo ambiental de residuos, durante la operación y rehabilitación final de las minas. Por ejemplo: los relaves (residuos generados durante el procesamiento mineral) fueron depositadas como lechadas diluidas en los cuerpos de aguas, y los desmontes (desechos generados durante la extracción mineral) depositados sobre la superficie del suelo, sin considerar ningún tipo de medida de control y protección que evitara la dispersión y movilidad de los residuos.

En la actualidad en algunos casos las colas son descargadas en los ríos, lagos y océanos, por las desventajas que presenta la disposición de las colas en términos de construcción de presas, uso y economía. En otras situaciones, el vertido se realiza en húmedo, pero esto presenta inconvenientes debido al riesgo de contaminación de aguas subterráneas y la dificultad de rehabilitar los sitios de almacenamiento. Por lo tanto, dado esta problemática se han sustituido las colas en lechadas diluidas, por técnicas en disposición en seco.

El marco legal que regula la industria extractiva en países de amplia tradición minera ha estado en constantes cambios y reformas en función de mejorar los mecanismos y procedimientos que regulan las actividades mineras, con énfasis en promover y fomentar el uso de tecnologías amigables con el medio ambiente. Por consiguiente, ha obligado a las empresas mineras a responsabilizarse y ajustarse a lo establecido en la legislación hasta el punto que la mayoría de las empresas han ido más allá y optado por la certificación ISO 14001. De tal forma, el contexto en que se ha desarrollado la minería ha contribuido a la sostenibilidad ambiental de la industria minera en algunos lugares del mundo.

Particularmente, la legislación que regula la minería en Nicaragua, está constituida principalmente por la ley especial de exploración y explotación de minas (Ley 387) y sus reformas. Así mismo, por los reglamentos de la Ley 387 (decretos 119-2001), reglamento de permiso y evaluación de impacto ambiental (decreto 45 94), de las disposiciones para el control de contaminación proveniente de descargas de aguas residuales domésticas, industriales y agropecuarias (decreto 33-95), del formulario para concesionarios mineros (acuerdo ministerial 533-RN-MC-2006), y se complementa con la ley general de las aguas (Ley 620), ley general del medio ambiente y recursos naturales (Ley 217), y ley especial contra delitos ambientales y recursos naturales (Ley 559), entre otras.

En ninguna de las leyes, decretos y acuerdos ministeriales normados en Nicaragua se establece el procedimiento para caracterizar las colas, así como las especificaciones y criterios para la caracterización y preparación del sitio, proyecto, construcción, operación y pos operación de presas de colas. Así mismo, no se regulan los elementos y procedimientos para instrumentar planes de manejo de residuos mineros. Por otro lado, no se estipulan los requisitos de protección ambiental para los sistemas de lixiviación de minerales de oro y plata. Otro de los vacíos en la legislación minera nicaragüense es la inexistencia de guías ambientales para el manejo sostenible de colas, desmontes y drenaje ácido de minas.

En cuanto a la aplicación de la legislación minera nicaragüense, los estudios de evaluación de impacto ambiental y consultas públicas son primicias que las empresas mineras deben cumplir para recibir los permisos ambientales. Por otro lado, las descargas de los efluentes generados por la industria minera deben de cumplir con 
los parámetros establecidos en el decreto nacional 33-95. El cumplimiento de la normativa nacional es regulada por las instituciones gubernamentales vinculadas con el sector minero, quienes se encargan de realizar supervisiones y monitoreo en áreas destinadas para la exploración y explotación de minas. Sin embargo, las actividades realizadas para la regulación y control de la actividad minera en Nicaragua no son suficiente si se toman en cuenta los altos riesgos que traen sobre la salud y el medio ambiente.

En la actualidad en el país existen tres minas en explotación localizadas en el Limón (León), La Libertad-Santo Domingo (Chontales), Bonanza (Región Autónoma del Atlántico Norte) y probablemente se desarrollen minas en La India (León) y San Albino (Nueva Segovia).

Las minas tienen un tiempo de vida útil, que depende en gran medida de la existencia y agotamiento de las reservas minerales. Por lo tanto, las minas en explotación en Nicaragua no son excluyentes a este principio y tarde o temprano tendrán que cerrar operaciones.

De acuerdo a la revisión de la legislación nacional, en Nicaragua no existe ningún instrumento legal que regule los cierres y pos cierres de minas. Los conceptos de cierre y pos cierre no necesariamente significa terminar operaciones. Son una serie de actividades que se realizan a lo largo de la vida útil de la mina. Tienen por finalidad resguardar la protección y salud de las personas del entorno de las minas, sin excluir el medio ambiente. Así mismo, incluyen la rehabilitación y restauración de los sitios mineros. Por consiguiente, es de suma importancia que el gobierno inicie el proceso de formulación de una normativa, que regule los planes de cierre y pos cierre de minas, si realmente se quiere velar por evitar problemas de índole ambiental, institucional, legal y de salud pública.

Por otro lado, hay que dar especial atención a los pasivos ambientales generados por las industrias mineras en el pasado, particularmente los pasivos localizados en las antiguas minas (Topacio, Reina, Vesubio, Siuna y Rosita). En principio deben ser caracterizados y evaluados en cuanto a la peligrosidad, para posteriormente proponer un plan de manejo de residuos mineros. De lo contrario, pueden convertirse en fuentes puntuales de contaminación que consecuentemente pueden afectar la seguridad de la población.

En Nicaragua, en términos de instancias académicas y capacidades humanas se pueden mencionar algunas debilidades. Primeramente no existe ninguna universidad o institución que impartan carreras profesionales relacionadas con ingeniería de minas, metalurgia extractiva y particularmente sobre el manejo y gestión integrada de residuos de minas, a excepción de carreras afines a las ciencias de la tierra, que ofrecen la Universidad Nacional Autónoma de Managua (UNAN), la Universidad Centroamericana (UCA) y la Universidad de Ingeniería (UNI). Por lo tanto, en el presente no existen profesionales con suficiente conocimientos técnicos específicos, preparados para enfrentar y resolver los problemas ambientales generados por la industria minera en el país.

En conclusión, la estructura del sector minero nicaragüense presenta muchas debilidades y, por consiguiente, los instrumentos legales, los mecanismos de gestión ambiental, las instancias gubernamentales y las capacidades humanas, deben ser fortalecidos y mejorados si se quiere que la minería en Nicaragua sea una actividad responsable, segura y sostenible. 